\title{
On Dormitory Cultural Construction of Vocational Colleges
}

\author{
Zhang Bin ${ }^{1}$, Zhang Qian², Liao Xiuyong ${ }^{2}$ \\ ${ }^{1}$ North Sichuan College of Preschool Teacher Education, Guangyuan, Sichuan, 628017 \\ ${ }^{2}$ China Sichuan Engineering Technical College, Deyang, Sichuan, 618000
}

\begin{abstract}
Dormitory cultural construction has been the focus and difficulty of campus cultural construction for colleges. The research group, based on the analysis of the status of dormitory cultural construction of the representative 10 vocational colleges in Sichuan province, investigates the connotation and characteristics of dormitory culture and probes the current status of dormitory cultural construction. And the research group, exploring the ways and means of dormitory cultural construction with Sichuan Engineering Technical College as the research objective, proposes a framework of dormitory cultural construction which consists of operation mechanism, management system, quality nurturing, carrier of students' activities and humanities environment for vocational colleges, which solves students' dormitory management challenges and highlights students training characteristics for vocational colleges.
\end{abstract}

Index Terms - vocational colleges, dormitory culture, research

\section{Introduction}

Modern Chinese New Dictionary defines dormitory culture as the general cultural activities carried out on the basis of dormitory. Dormitory culture is the refraction of campus culture and extension of family culture and enrichment of social culture. Dormitory for college students is the first society, the second family and the third class as dormitory is the major places for their learning, living, resting, entertainment and communication. [1] In recent years, colleges have achieved outstanding results due to their great cultivation of the spirit of college, campus culture. However, dormitory cultural construction has been the focus and difficulty of campus cultural construction for colleges and is in short of systematic research. The research group, based on the analysis of the status of dormitory cultural construction of the representative 10 vocational colleges in Sichuan province, investigates the connotation and characteristics of dormitory culture and probes the current status of dormitory cultural construction. And the research group, exploring the ways and means of dormitory cultural construction with Sichuan Engineering Technical College as the research objective, proposes a framework of dormitory cultural construction which consists of operation mechanism, management system, quality nurturing, carrier of students' activities and humanities environment for vocational colleges, which solves students' dormitory management challenges and highlights students training characteristics for vocational colleges.

\section{Basic Connotation of Dormitory Cultural Construction for Vocational Colleges}

College campus culture is composed of dormitory static material culture, system culture, spiritual culture with personality characteristics, and dynamic activities culture. It reflects the spirit of a college with clean, elegant and civilized campus cultural environment, which stimulates the curiosity of students, motivation of students and faculty members.[2] Vocational college dormitory culture is the key part of campus culture with its special cultural connotation and personality trait.

\section{A. Material culture is the basic connotation of dormitory cultural construction for vocational colleges}

Material culture is the physical presence of dormitory culture and expression of college management and Educational philosophy, which includes concerned facilities and environment for students. Such sophisticated design for student's dormitory as walls talk and flowers smile can enhance students' home identity, sense of belonging, which arouses students' effort to skills training to be a skilled talent. And it can train student's ability and reflect the characteristics of vocational student's development by mobilizing students to design their own dormitory atmosphere based on their learning majors. Material culture is the basic guarantee in training students imperceptibly in campus cultural construction

\section{B. Spiritual culture is the dominate connotation of dormitory cultural construction for vocational colleges}

Dormitory is the major places for students to take part in social and moral activities, which is regarded as the second front for ideological and political education. Dormitory spiritual culture is composed of the awareness of students' compliance with laws and regulations and social ethics, professionalism and concept of collectivism, quality of hard work and thrifty, cultivation of aesthetics and basic civilization, as well as group mentality and campus media. And it, which is interwoven with students' ideological and moral education, is the core content of dormitory cultural construction for vocational colleges.

\section{Systematic culture is the assured connotation of dormitory cultural construction for vocational colleges}

Systematic culture of students' dormitory is a kind of social relationship and regulation formed in the process of their social activities, which consists of various rules and regulations, codes of conduction, rating system, incentives and disincentives, as well as its implementation and monitoring system. Systematic culture of students' dormitory, with its mandatory and non- mandatory power, maintains the cultural value of identity and binds on its members' behavior and 
psychology. Dormitory culture is a long-term complex system. Therefore, it is inevitable to build up a reasonable and effective management system that all the faculty members take part in for dormitory cultural construction for vocational colleges.

\section{Cultural activities is the expanding connotation of dormitory cultural construction for vocational colleges}

Dormitory is the living community for students' learning and entertainment, which results in a variety of natural, social and cultural interaction upon students' activities. Cultural activities is a student- centered group culture, in which there are various interesting activities, practical activities, sports and reading activities within students' living dormitory community. It is the important feature for vocational colleges' dormitory cultural construction to carry out a variety of activities based on quality education, to innovate the carrier of cultural activities, to improve students' overall training skills and professionalism [3]

\section{The Present Status of Dormitory Cultural Construction for Vocational Colleges}

The research group has taken the thematic research by using questionnaires, spot-visits, thematic seminars about dormitory cultural construction for vocational colleges. The research group distributed 2,000 copies of anonymous questionnaire in 10 vocational colleges in Sichuan Province, China from October to December, 2011 and 1,907 copies were taken back. According to this survey, dormitory culture is concerned with students' healthy growth, quality improvement and intellectual pursuit. Therefore dormitory culture has become an integral part of campus dormitory construction for vocational colleges and is strongly demanded by contemporary college students.

\section{A. Achievements}

The living environment for students has been optimized with improvement of infrastructure construction.

Currently the infrastructure construction has been improved greatly in vocational colleges which satisfied the demand of students, in which there are network ports, telephone, electric fans and other basic living facilities in their perfect status. And there are playgrounds, library, newspaper reading places, bathrooms and other public facilities. According to the survey, $45.2 \%$ of students are satisfied with their living accommodation and facilities. However, the survey shows that there is a large space for improvement in dormitory environment and infrastructure construction.

The relationship between dormitory members is harmonious with their positive mental outlook.

According to the survey, the focuses are mainly learning contents, current affairs, and social recreational activities during their chat inside their dormitory. More than $94.2 \%$ of the students describe that their relationship is very harmonious or they get well along with each other. $53.3 \%$ of the students says that they visit and chat with their neighbour dormitory members. $84.5 \%$ of the students says that they are willing to hold birthday party or give their blessings for their member in the same dormitory. It shows the positive role of dormitory cultural construction due to the students' positive mental outlook, harmonious relationship, as well as their strong sense of belonging.

The function is recognized and the regulated effect is to work in dormitory culture.

According to the survey most students realize that their personal behavior is closely related to behavior habits, style and learning atmosphere. Therefore, they welcome dormitory management rules of long-term inspection in such filed as hygiene condition. $71.4 \%$ of the students keep on doing cleaning work everyday and 73.9 of the students have decorated their bedrooms. Most interviewees in this research say that dormitory culture is an important part of campus culture, in which campus spirit is interrelated with learning atmosphere and dormitory culture. Its incentive, educational and regulated functions are generally recognized.

Dormitory cultural activities are carried out with a high degree of students' participation.

At present, there are many types of dormitory cultural activities concerned with culture, sports, entertainment and morality, by holding evenings, lectures, competition and other forms. $72.7 \%$ of the students choose either partially or willingly to take part in dormitory activities hold by the college, departments, class, as well as other organizations. There is a huge attraction for college students during dormitory cultural activities, which has become one of the most important ways to enhance their ability.

There are sound systems as for dormitory with better compliance of students.

$85.5 \%$ of the students express that there are sound and reasonable management system concerned with dormitory safety, sanitary condition, activities, service, management and evaluation. And $43.9 \%$ of their dormitory has various rules and regulations or their own oral agreement between members with better compliance. According to the survey, dormitory cultural system construction has been made progress because that most college students can consciously abide by the rules and regulations concerned with dormitory from the aspect of system development, compliance status, and evaluation of management department.

\section{B. Deficiencies}

There is in short of overall planning in dormitory cultural construction and lack of joint management mechanism.

Some vocational colleges do not pay sufficient attention to dormitory cultural construction and failed to form the joint management mechanism of functional departments and teaching departments. Other vocational colleges concentrate on their effort in dormitory cultural construction directly to dormitory members, and there are many kinds of activities held by students union, teaching departments and students clubs, in which there is insufficient overall linkage and lack of effective integration of resources which results in students' participation dispersion phenomena. Therefore, it restricts the function of dormitory cultural activities.

Service awareness is neglected and dormitory 
management system is not reasonable in a certain degree.

From the survey, $31.4 \%$ of the students are dissatisfied with access to dormitory rules. And $27.8 \%$ of the students are dissatisfied with safety rules. And $23.6 \%$ of the students are not satisfactory with inefficiency effort towards bad living and behavior habits administration. However, $61.5 \%$ of the students think that dormitory is their private and free space then they think there be much better if there are less rules and regulations towards dormitory administration, which reflects student's alienation of management system. Currently, many administration departments pay much effort to mandatory and punishment while they pay less attention to humanitarian concern to students. And students' self-management needs to be improved with system implementation during dormitory cultural construction.

Dormitory cultural activities are paid attention to its superficiality and lack of dormitory cultural construction brands.

Although there are various dormitory cultural activities, most of them pay attention to the form instead of content. And these activities are in short of orientation and innovation due to its delay of adjustment to the change of internet influence. Some activities are held only for entertainment purpose, lack of the educational and guiding function, and lack of the value pursuit of culture. There is a big gap between the demand and the status in Dormitory cultural activities for vocational colleges.

Lack of comprehensive assessment and objective of dormitory cultural construction

Some vocational colleges think that dormitory cultural construction is only to hold cultural activities and routine management, without fully understanding of its function and objective, ignoring the dormitory as the management rule of the ideological and political education, as well as mental health education. $14.5 \%$ of the students will ask for help form counseling teachers when facing psychological stress, confusion or obstacles. However, $38.4 \%$ of the students choose to repress that or other ways to do that. Only $6.4 \%$ of the students choose that dormitory has a positive impact with its landscape, decoration, facilities and motto.

Outstanding management resources are deficient and the management team needs to be upgraded.

At present in many vocational colleges, a full-time counselor usually covers $200-300$ students. Therefore, $55.4 \%$ of the students say that their counselor seldom goes to their dormitory. While $16.3 \%$ of the students say that their counselor goes to their dormitory around 10 times a term without fully communication and guidance with them. According the questionnaire, $42.5 \%$ of the students insist that building up a management team with high quality is the key for dormitory cultural construction. It is imminent to improve the management team who will instruct and give guidance to their students.[4]

\section{Approaches to Dormitory Cultural Construction for Vocational Colleges}

It is a complete system in theory for dormitory cultural construction for vocational colleges and a systematic project in practice. Therefore, it is needed to overall design and to explore building up paths so that vocational colleges can ensure its fully function of dormitory cultural construction from the inspective of material culture, system culture, spiritual culture, as well as operational mechanism.

The research group summarizes the achievement, and explores the approaches using Sichuan Engineering Technical College(SETC) as the research objective.

\section{A. Pay attention to joint action mechanism and dormitory cultural construction mechanism}

Dormitory cultural construction is a systematic project. And that calls for such mechanism as colleges should pay attention to scientific planning, coordinating management, and departments to full coordination and join action, and students to self-management and group cohesion. It is necessary to establish a vertical coordination network of the Party, administration, students and the Youth league, together with student Party members group, students dormitory management committee, student dorm leader, so that these departments work together for its powerful force under the leadership of a stable dormitory cultural construction management and guidance institution.

SETC puts its effort to establish the objective of dormitory cultural construction that dormitory is the classroom for students' good habit, rigorous life style, healthy aesthetics, and teamwork awareness. SETC puts up the management committee, in which the deputy president is leader, while the director of student affairs and the director of the general services as the deputy leader, with leader members from the logistics service center, security office, the Communist Youth League, and the leaders from teaching departments. SETC establishes the Party branches for students in dormitory so that the carders and the Party members are designated to contact certain students in dormitory. And there is a student self-management committee. SETC has established a network of dormitory cultural construction due to its clear division of work, close coordination, joint action.

\section{B. Pay attention to establish a dormitory cultural construction mechanism}

A sound rules and regulations of dormitory, in which the implementation of that will create a good environment of a rule-based management, fair competition and self-taught for students, which can greatly facilitate them to develop good habits and manners of civilization, and self-discipline with the outer help from the rules and regulations.[5] It is necessary to pay attention to serious authoritative, fair and reasonable balance in its planning, construction, supervision, assessment system improvement.

SETC has established a set of practical rules and regulations such as student dormitory civilization implementation guidance, student dormitory daily behavior regulations, youth civilization demonstration dormitory ratio standards, which covers the ideological and political education, student behavior specifications, dormitory safety and health, property management, network management, as 
well as activities management. The dormitory cultural construction is linked with the assessment of teaching departments efficiency of students' affairs, dormitory buildings management efficiency, and the assessment of student who wants to take part in the Party, their opportunity to transfer to other universities, as well as their jobexpectation. With the in-depth explanation and strict enforcement of these rules and regulations, SETC ensures the establishment of the safe and orderly learning environment, and the formation of a healthy and positive dormitory atmosphere.

\section{Pay attention to civilized self-cultivation and implementation of professionalism}

Dormitory is an important position for students' quality education. And the experience for a lot vocational colleges is that a good dormitory environment is linked with a good campus environment, a good learning atmosphere is linked with no student indulging in computer games in their dormitory, and a positive attitude towards one's dormitory work is linked with the establishment of basic habits of civilization. And it is necessary to train students from literacy explanation into their intrinsic understanding, and have their own experience of this successful implementation within the platform of dormitory cultural construction.

SETC works from the weak places, turns the dormitory into a classroom, expands self-cultivation of civilization, and implementation of professionalism. Each dormitory building provides students with newspapers reading places, cultural activities room, video- watching hall, and campus radio into every dorm so that students can touch these public opinion and advanced ideas. SETC engages in carrying out the demonstration dormitory of student member of the Party, the best learning atmosphere dormitory, the demonstration dormitory in healthy, and the best cultural atmosphere dormitory, through which dormitory cultural construction is linked with the five-star dorm standards.

One can see the bright floors, clean walls, and neat toiletries in students' dormitory. Students develop their rigorous life-style and good professionalism with day after day's hard work for three years in colleges, which is unanimously approved by the employer.

\section{Pay attention to innovative design and creation of dormitory cultural activities}

Activity is the primary work for dormitory cultural construction. The design for dormitory cultural activities should combine the student characteristics with college feature, and combine cultural activities with their major, which will give full play to the role of student organizations to carry out various interesting activates, practical activities, sports activities, and reading comprehension activities to enhance students' professionalism and career skills.

The following four measures are in practice of SETC cultural activities. The first is to develop learning atmosphere construction activities, such as contest and debate towards major current events and focus, and learning model dormitory selection. The second is to hold cultural and recreational activities aim for taste pursuit by holding one cultural and sports activity per month as for each dormitory building, by holding one dormitory cultural festival per year. The third is to hold activities concerned with the Party and the Youth league, combined with dormitory cultural activities, in which the Party members are supposed to contact certain dorms with voluntary services. And that put ideological and political education at the student home, their dormitory. The fourth is to organize work-study activities with the creation of loveflow station. SETC has published the newsletter of dormitory center distributed to every teaching department and class. And the newsletter is concentrated on the exhibition of dormitory cultural activities.

\section{E. Pay attention to improve quality and optimize humanitarian environment}

People say that human being creates the environment and the environment creates human being. The humanitarian environment construction is the exemplification of educational philosophy. And a beautiful dormitory environment can train students in an invisible way.

SETC has named three student dormitory areas as pine garden, plum flower garden, and bamboo garden, around which area there are lots of pine trees, plum flowers and bamboo so that the students are supposed to be a upright man. There are decorated with mottos of those National Skills Competition masters, photos of the distinguished Alumni in the halls and corridors around dormitory areas. And the speechless lake, the stone carved with the ode of SETC, cultural activities house, as well as newspaper reading places, all reveal the harmonious cultural atmosphere. The workers at the dormitory management have been played the two roles. The first is to be a kind mentor with civilized behavior and communicating with mandarin of students. And the second is to be a good friend who cares about everything from the students. And each dormitory building provides humanitarian services with cultural activities house, TV programs watching hall, storage lockers. And the staff will keep messages of visitors, provide minor repairs work, as well as food and medicine heating for students. The harmonious and mutual understanding relationship inside dormitory has been improving students' self-esteem and cultivation of caringothers personality.[6]

\section{References}

[1] Li Mingming, Zhi Guangyuan, Fu Sheng, On Dormitory Cultural Construction from the Perspective of Quality of Nurturing, The Journal of Xinxiang Education College, 2009, 4:8.

[2] Cao Yunfeng, On Material Culture Construction as the Curing Carrier of Campus Culture, Harbin Institute of Technology Newspaper, 2008-0702.

[3] Liao Xiuyong, On Dormitory Cultural Construction Connotation of Vocational College, Contemporary Vocational Education, 2012, 4:75-78.

[4] Zhang Bin, Zhang Qian, Liao Xiuyong, Survey and Consideration on Dormitory Cultural Construction of Vocational College, Contemporary Vocational Education, 2012, 6:58-61.

[5] Ouyang Shuqing, On Building Excellent Campus Culture for Colleges, The Journal of Jiangxi Administration Institute, 2004, 4:77.

[6] Zhang Bin, Zhang Qian, Liao Xiuyong, Exploration and Practice of Dormitory Culture Construction of our College, Chinese Vocational and Technical Education, 2012, 1:58-59. 